\title{
Sulfone-carbonate ternary electrolyte with further increased capacity retention and burn resistance for high voltage Lithium ion batteries
}

\author{
Leigang Xue ${ }^{\mathrm{a}}$, Seung-Yul Lee ${ }^{\mathrm{a}}$, Zuofeng Zhao $^{\mathrm{a}}$ and C. Austen Angell ${ }^{\mathrm{a}}$ \\ ${ }^{a}$ Dept. of Chemistry and Biochemistry, Arizona State University, Tempe AZ 85287-1604, \\ USA \\ austenangell@gmail.com
}

\begin{abstract}
Safety and high energy density are the two focus issues for current lithium ion batteries. For safety, it has been demonstrated that sulfone electrolytes are much less flammable than the prevailing all-carbonate type, and they are also promising for high voltage batteries due to the high oxidization resistance. However, the high melting points and viscosities greatly restricted their application. Based on our previous work on use of fluidity-enhancing cosolvents to make binary sulfone-carbonate electrolytes, we report here a three-component system that is more conductive and should be even less flammable while additionally having better low temperature stability. The conductivity-viscosity relations have been determined for this electrolyte and are comparable to those of the "standard" carbonate electrolyte. The additional component also produces much improved capacity retention for the $\mathrm{LiNi}_{0.5} \mathrm{Mn}_{1.5} \mathrm{O}_{4}$ cathode. As with carbonate electrolytes, increase of temperature to $55^{\circ} \mathrm{C}$ leads to rapid capacity decrease during cycling, but the capacity loss is due to the salt, not the solvent. The high discharge capacity observed at $25^{\circ} \mathrm{C}$ when $\mathrm{LiBF}_{4}$ replaces $\mathrm{LiPF}_{6}$, is fully retained at $55^{\circ} \mathrm{C}$.
\end{abstract}

\section{Keywords}


Lithium ion battery; electrolytes; low flammability; high voltage; sulfone eutectic

\section{Introduction}

Rare but fiery accidents with all-electric vehicles serve as a reminder that electrochemical technology has not yet provided us with fully safe emission-free automobile power trains. Risk lies mainly in the electrolytes, highly flammable acyclic carbonate being the leading risk solvent in current batteries. We have recently shown that electrolytes with high sulfone content can provide excellent electrochemical performance with high voltage cathodes[1], while Amine and others[2-4] have shown that such electrolytes are much less flammable than the standard (carbonate) electrolytes.

The oxidation resistance of acyclic sulfones has actually been recognized for some time[ $[5,6]$. What has been more recently discovered is that sulfones can be combined with less oxidation resistant but fluidity-enhancing cosolvents without losing their oxidation resistance.[1,6] This has been shown, by simulation studies[7], to be due to a preferential (and protective) ordering of sulfone molecules near the electron-rich highly positive-charged surface of the cathode. With the emergence of $5 \mathrm{~V}$ class spinel $\left[\mathrm{LiNi}_{0.5} \mathrm{Mn}_{1.5} \mathrm{O}_{4}\right.$ (LNMO), 4.6 V][8] or cobalt phosphate $\left(\mathrm{LiCoPO}_{4}, 4.8 \mathrm{~V}\right)[9]$ cathodes, whose operating potentials lie beyond the expected stability limits of the carbonate-based electrolytes $(4.5 \mathrm{~V}),[10]$ this sulfone-carbonate electrolyte synergism would seem to be an important development. While there is some concomitant decrease in safety from the carbonate co-solvent addition, the sulfone-carbonate binary electrolyte is still far safer than the commercialized all-carbonate electrolytes. 
In recent papers $[1,11]$ we explored the ionicities, and half cell performances, of $1 \mathrm{M}$ $\mathrm{LiPF}_{6}$ solutions in a variety of binary solvents that contain one or other sulfone as the polar (ion solvating) component together with a low dielectric constant but high fluidity acyclic carbonate, as the co-solvent. We showed that the combination ethylmethylsulfone (EMS) + dimethyl carbonate (DMC) provides very favorable electrochemistry at both the high voltage LNMO cathode and the lithium titanate $\left(\mathrm{Li}_{4} \mathrm{Ti}_{5} \mathrm{O}_{12}, \mathrm{LTO}\right)$ anode.

In the present extension of our studies, we have incorporated the smaller, more highly polar, but higher melting dimethyl sulfone (DMS) in proportions to minimize the binary sulfone liquidus temperature.[12, 13] The eutectic temperature of the simple binary system lies at $23{ }^{\circ} \mathrm{C}$, far below the melting point of DMS $\left(110^{\circ} \mathrm{C}\right)$ and also EMS $\left(36.5^{\circ} \mathrm{C}\right)$. The addition of electrolyte salt and the low-melting DMC of course lead to a substantial further stabilization of the liquid, which we document herein. The design consideration of this ternary electrolyte can be outlined as in Figure 1.

While stabilizing the electrolyte for lower temperature application is important, our initial interest was in finding whether the conductivity and ionicity could be incrementally increased by incorporation of the smaller, highly polar sulfone DMS. While this improvement has indeed been realized, a more important and unexpected improvement has been found. This is that, in half-cell testing with the high voltage LNMO cathode, we find we have obtained a much smaller rate of capacity loss than the already small value for the two component solvent case reported previously.[1] Moreover, with only two $\mathrm{CH}_{3}$ groups per molecular DMS (see Figure 1) compared with the four in sulfolane,[2] the burn resistance should also be enhanced. 
Not surprisingly, the excellent performance found with the ternary solvent electrolyte is not maintained at $55^{\circ} \mathrm{C}$, but this is not a solvent problem. It is due to intrinsic $\mathrm{PF}_{6}{ }^{-}$thermal instability, which we establish by replacing the $\mathrm{PF}_{6}{ }^{-}$anion with the more thermally stable $\mathrm{BF}_{4}{ }^{-}$anion and showing we can obtain a temperature independent cycling performance. We report these substantial improvements in sulfone electrolyte technology below.

\section{Experimental}

EMS (>98.0\%) and DMC (>98.0\%) were purchased from TCI company, and all other chemicals used were bought from Sigma-Aldrich, all used without further purification. A known mass of EMS was first heated at $50{ }^{\circ} \mathrm{C}$ to obtain the liquid state, and the mass of DMS needed for the desired sulfone composition then dissolved. The EMS 85mol\%-DMS $15 \mathrm{~mol} \%$ mixture stays liquid at room temperature due to proximity to the eutectic composition. DMC was then added to obtain (EMS85-DMS15)-DMC ternary solvent, which is reported in weight \% DMC, or weight ratio DMC. Finally $\mathrm{LiPF}_{6}$ was added to the solvent to obtain an electrolyte with a concentration of $1 \mathrm{~mol} \mathrm{~L}^{-1}$.

For the $\mathrm{LiNi}_{0.5} \mathrm{Mn}_{1.5} \mathrm{O}_{4}$ cathode, preformed sheets were provided by Hydroquebec Co. under arrangement with the DOE LBL-BATT research program. They comprised LNMO 89\%, carbon black 3\%, vapor grown carbon fiber (VGCF) 3\% and polyvinyl difluoride (PVDF) 5\% in mass.

Viscosity measurements were performed using a Cannon-Manning viscometer, which was calibrated by the manufacturer. The temperature was controlled to $\pm 0.1^{\circ} \mathrm{C}$ by means of a water circulating bath (LC20, Lauda). 
Solution densities were measured with accuracy sufficient for obtaining equivalent conductivities for our Walden plots $(\sim 1 \%)$, simply by measuring the weight of the sample filling a $1 \mathrm{~mL}$ volumetric flask at different temperatures. Before each measurement, the flask was maintained in an aluminum block at the desired temperature for $0.5 \mathrm{~h}$ to obtain a uniform temperature.

Ionic conductivities were measured by the standard complex impedance method, using a PARSTAT2273 apparatus (Princeton Applied Research) with a frequency range of $10 \mathrm{~Hz}$ to $1 \mathrm{MHz}$. The electrolytes were contained in a dip-type cell with twin platinum electrodes. The cell constant of $17.07 \mathrm{~cm}^{-1}$ was determined using $0.01 \mathrm{M} \mathrm{KCl}$ aqueous solution. The temperature was controlled by a Peltier temperature controller with an aluminum block for lower temperature and a thermostatted chamber (DKN402, Yamato) for higher temperature.

The thermal transitions, melting point $\left(\mathrm{T}_{\mathrm{m}}\right)$, crystallization temperature $\left(\mathrm{T}_{\text {cry }}\right)$, and glass transition temperature $\left(\mathrm{T}_{\mathrm{g}}\right)$ were determined using a differential scanning calorimeter (DSC-7, Perkin_Elmer). For DSC measurements, the instrument was calibrated prior to the measurements by the two-point method with indium $\left(\mathrm{T}_{\mathrm{m}}=156.6{ }^{\circ} \mathrm{C}\right.$ and cyclohexane (solidsolid transition, $\mathrm{T}_{\mathrm{S} 1 \rightarrow \mathrm{S} 2}=-86.6{ }^{\circ} \mathrm{C}$ ) as the standard samples for high temperature and low temperature regions, respectively. Samples $(\sim 10 \mathrm{mg})$ were sealed in aluminum pans and scanned at a rate of $20 \mathrm{~K} \mathrm{~min}^{-1}$ in a helium atmosphere.

The cyclic voltammetry (CV) of the ternary electrolyte was determined using a potentiostat/galvanostat (Princeton Applied Research, VMP2). A three-electrode cell was employed with platinum as the working and counter electrodes, and lithium metal as the 
reference electrode. The test was made at room temperature at a scan rate of $5 \mathrm{mV} \mathrm{s}^{-1}$ with the voltage range of -0.3 to $6.3 \mathrm{~V}$.

The battery performance of the electrolytes with cathode was evaluated by using lithium-ion half-cells. Coin-type 2032 cells (20 mm diameter, $3.2 \mathrm{~mm}$ thickness) were assembled in an argon glove box with lithium as the counter electrode. Coin cell kits were purchased from MTI Corporation. The negative covers, spacers and springs were made of stainless steel 316 (SS-316), and the positive containers were Al-clad SS-316 to avoid the corrosion of stainless steel by electrolytes over $4.0 \mathrm{~V}$. Fiber glass separators were used instead of conventional separators (polyethylene or polypropylene), which have a wettability problem in contact with sulfone molecules.[2, 14] Charge/discharge tests were performed using a LAND CT2001A battery testing system, using groups of 3 or 4 nominally identical coin cells to check for consistency.

\section{Results and Discussion}

\subsection{Conductivity}

With respect to our initial objective of improving conductivity, we show in Figure 2 the conductivities of new solutions, $1 \mathrm{M} \mathrm{LiPF} 6$ in (EMS85-DMS15)-DMC in two proportions (1:1 and 3:7 by wt.). Figure 2 also includes conductivity of the two-component solution EMS-DMC that was the solvent of choice for our most recent study of half cell performance.[1] Again we include data for 1:1 and 3:7 ratios. The insert shows data for the latter solution obtained during cooling, following the initial heating run, to demonstrate that the results are reproducible and free of any distortions from loss of volatile components. Included for comparison are the data for the "standard electrolyte", $1 \mathrm{M} \mathrm{LiPF} 6$ in EC-DMC 
(1:1 by wt), which remains the best conductor of the series but now by only a factor of 2 . With the addition of DMS, not only has the conductivity gap been decreased, but the resistance to inflammation has been increased. The low-flammability character of the sulfones is maximized in the low-hydrocarbon content case of the DMS component, although the flash point will still be determined by the more volatile acyclic carbonate.

\subsection{Low temperature stability}

To establish the low temperature stability of the electrolyte we use differential scanning calorimetry to show the phase behavior during reheating. We show in Figure 3 the thermogram obtained at the $20 \mathrm{~K} \mathrm{~min}^{-1}$ heating rate, after an initial cooling at the same rate. The upscan thermogram shows a glass transition at $-108{ }^{\circ} \mathrm{C}$ followed by a series of secondary crystallizations and then the redissolution of primary crystals, commencing at $26^{\circ} \mathrm{C}$ and concluding at $-15^{\circ} \mathrm{C}$. During cooling at $1 \mathrm{~K} \mathrm{~min}^{-1}$ the primary crystallization does not occur before $-31^{\circ} \mathrm{C}$ so the stability of the electrolyte to changing temperature, is satisfactory.

\subsection{Ionicity}

To assess the ionicity of these solutions, we need additional solution data, namely viscosity and density, in order to construct the Walden plot that may be used to compare new electrolyte performance with that of an ideally ionic solution - as demonstrated in previous ionic liquid and solution studies[11, 15]. Miran et al.[16] have shown that there is a good correlation between the ionicity obtained from the Walden plot and that obtained by more demanding diffusivity measurements through the Nernst Einstein equation. We may expect fairly high ionicity in the present solution as the dielectric constants of EMS and its eutectic 
mixture with DMS are high (56.9 and 61.2, respectively, while the less viscous mixture EMS-DMC (1:1 by wt.) has the lower value 25.5 (R. Richert (private communication, see acknowledgements)). Higher and lower values reported for EMS elsewhere must contain some source of error.

We have obtained viscosity and density data for the two DMS-containing solutions of Figure 2. In Figure 4 we plot the equivalent conductivity against the inverse viscosity using log scales, along with a selection of previous data, to show that the DMS-containing solutions in 1:1 sulfone : $\mathrm{DMC}$ as solvent, are actually more ionic, i.e. the $\mathrm{LiPF}_{6}$ electrolyte salt is more dissociated in EMS-DMS-DMC solvent than in the corresponding EC:DMC solvent - which we call the "standard" lithium ion battery electrolyte. A fully ionic solution would have an equivalent conductivity that falls on the Walden ideal line which is calibrated by $1 \mathrm{M}$ aqueous $\mathrm{KCl}$.

The importance of this observation is the recognition that, although the standard electrolyte has a marginally higher conductivity at $25^{\circ} \mathrm{C}$ than the new sulfone electrolyte, it achieves this at the cost of ionicity. In detail, the $25^{\circ} \mathrm{C}$ equivalent conductivity point for the standard electrolyte falls almost an order of magnitude below the ideal line, implying that $90 \%$ of the ions in the solution are tied up as non-conducting ion pairs. Low ionicity predisposes the electrolyte to concentration polarization and efficiency loss during charging and discharging. In the corresponding sulfone-containing solutions at the same 1:1 wt. ratio of ionizing solvent to co-solvent, the corresponding conductivity lies only one half order of magnitude below the ideal line, implying that some $30 \%$ of the ions are free to conduct charge. 


\subsection{Electrochemical window (oxidation resistance)}

The exceptional electrochemical window for the EMS-DMC solvent was shown in our previous report.[1] It is reproduced in Figure 5 in order to highlight the even wider window characteristic of the modified solvent of this work in which the sulfone component of the solvent has the molar composition $15 \%$ DMS $85 \%$ EMS. The increased stability no doubt reflects the reduction in the number of oxidizable $\mathrm{CH}_{3}$ groups in the solvent.

\subsection{Battery performance with high voltage LNMO cathode}

With the good ionicity, improved conductivity and oxidation resistance, now established, the final step is to evaluate the new electrolyte in half-cells. Here, the high voltage cathode LNMO was used as cathode, and lithium foil as anode. Galvanostatic charge/discharge tests were carried out between 3.5 and $4.9 \mathrm{~V}$ at $0.2 \mathrm{C}$. Figure 6a shows the typical charge/discharge behavior of the high voltage LNMO, indicating its compatibility with the (EMS85-DMS15)-DMC electrolyte. In our previous report we showed that the EMS-DMC 1:1 solution half-cell with high voltage cathode LNMO gave very encouraging cycling performance (shown in Figure 6b).[1] Here we want to make the comparison with solvent containing DMS. Since the EMS used in this work is the commercial product, and that used in the previous study was synthesized in-house, we need to repeat the study with binary solvent (EMS-DMC 1:1) using the same commercial source of EMS. The results for the new preparation, which now extend to 300 cycles, are included in Figure $6 \mathrm{~b}$. The rate of capacity decay is seen to be the same as that of the previous study (see dashed line extending the earlier data), but the capacity itself is about $10 \mathrm{mAh} \mathrm{g}^{-1}$ lower. 
Whatever the source of the difference between the two might be, it is overcome by the inclusion of DMS in the ternary solvent, the cell performance being dramatically improved. The capacity decay after 300 cycles for the cell with DMS included, is at least 3 times smaller than with the original binary solution. The first discharge capacity is 122 $\mathrm{mAhg}^{-1}$ (followed by an early increase to $130 \mathrm{mAhg}^{-1}$ ) and the capacity is still the same after 300 cycles.

Figure $6 \mathrm{c}$ presents the coulombic efficiencies versus cycle numbers for the same two electrolytes. The one with added DMS shows a small improvement over the one without DMS in the first 100 cycles, after which both of them reach $98.8 \%$ and become steady. The average coulombic efficiencies for the total 300 cycles are $98.3 \%$ and $98.0 \%$, respectively. The source of the poorer efficiency in the early cycles is not known but is likely to reside in solvent purity issues. An additional reason for including a repeat of the binary solvent electrolyte in this study was to see if there might be improvements in coulombic efficiency following our acquisition of a higher quality dry box for materials preparation and button cell production. We find that the battery performance for the binary solvent case has actually decreased, though this may be due to a decrease in solvent quality - which fortunately seems to be overcome by the inclusion of the third component DMS.

Coulombic efficiencies less than $100 \%$ can have multiple causes, among which side reactions and shuttle processes involving impurities, as well as solvent decompositions, may be counted. The formation of a protective interphase is obviously important in the case of solvents that are less oxidatively resistant than sulfones, such as the all-carbonate solvents of previous studies,[17] and they must be expected to play a role in the present case also. An important source of sulfone superiority may lie in its more Lewis acid character and the 
consequently reduced solubility of lower valence transition metal ions. Each of these factors merits further specific investigation.

In Figure 6d we address the concern with interrupted cycling. Dahn in particular has emphasized the importance of time of testing,[18] and related concerns with time-dependent stability were addressed in the comparisons of Demeaux et al.[19] In Figure 6d we show the results of a related test in which the cycling was arrested after 200 cycles, and then resumed after storage for 2 months. It is seen that the capacity lost $5-15 \mathrm{mAh} \mathrm{g}^{-1}$ in the first several cycles, but then recovered during subsequent cycles, indicating there was almost no irrecoverable capacity loss during the long period of inactivity. A reasonable surmise for the capacity loss and subsequent recovery would invoke the time-dependent consolidation of a protective layer (cathode SEI), during the two months "resting" period, and the reopening of the ion-conducting channels during several cycles of further testing.

Since the addition of DMS is obviously helpful to the battery performance, another test with more DMS, that is (EMS70-DMS30)-DMC (1:1 by wt.) solvent, was also tested. However, as we obtained almost the same performance in terms of capacity retention and coulombic efficiency, we do not show the data here.

We have reported in our previous work[1] that EMS-DMC-LiPF 6 electrolyte cannot be used with a graphite anode because it fails to form a protective SEI interphase. By contrast, the behavior at the alternative (and safer) lithium titanium oxide, LTO, anode, studied as cathode in a lithium half cell, was exemplary. The EMS-DMS-DMC-based electrolyte of the present study shows essentially the same (exemplary) behavior at the LTO electrode, and its performance in cycling is almost the same with the standard electrolyte 
EC-DMC. To conserve space, the further results are not shown here. Unless an effective SEI-forming additive can be found to render the sulfone-based solvent compatible with graphite, it would seem that full cells utilizing the present highly LNMO compatible and burn-resistant electrolyte, will have to be based on the pairing of LNMO with LTO.

\subsection{Higher temperature performance}

Since EV batteries are expected to run at temperatures of the order of $50-60^{\circ} \mathrm{C}$, the electrolytes need to possess elevated temperature stability, a long known weakness of those containing the salt $\mathrm{LiPF}_{6} \cdot[20,21]$ We have tested the present solutions at $55^{\circ} \mathrm{C}$, expecting them to fail because of $\mathrm{PF}_{6}^{-}$anion thermal instability. This is verified in Figure $7 \mathrm{a}$, which shows the rapid deterioration of the discharge capacity of the half-cell with $\mathrm{LiPF}_{6}$ electrolyte salt. This failure is in stark contrast with the performance of a half-cell which differs only by the replacement of $\mathrm{PF}_{6}^{-}$by $\mathrm{BF}_{4}^{-}$anions. In the latter case the test was carried out in two segments, first 20 cycles at ambient followed by rise of temperature to $55^{\circ} \mathrm{C}$ where another 20 cycles were carried out. It is seen that, temperature rise to $55^{\circ} \mathrm{C}$ had no effect on the capacity retention though it lowered the Coulombic efficiency markedly. $\mathrm{LiBF}_{4}$ is known to have poorer coulombic efficiency[18] than other lithium salts but our aim is only to establish that the failure of the successful electrolyte of Figures 1-6 is due to the salt, not the solvent component. In future work we hope to examine the cell performance with alternative salts such as $\mathrm{LiCF}_{3} \mathrm{BF}_{3}$ and $\mathrm{LiBF}_{3} \mathrm{TFA} .[22]$

\section{Conclusions}

Capacity retention in the case of half-cells with high voltage cathodes and sulfone-based electrolytes can evidently be tuned to be much better than was originally thought possible.[1] 
It is likely that the slow decay back to the initial capacity of $122 \mathrm{mAhg}^{-1}$ after 300 cycles, observed in this study, is not yet the optimum achievable with this solvent cathode system. Thus it seems that, provided the anode used is LTO (with which no decay at all was seen in our previous study), very long cycle life, and safe, batteries should be attainable.

Since the electrolytes in our tests were prepared using commercial solvents that were used without additional purification, it is reasonable to expect further improvements as electrolyte component impurities are improved. Solvent purification is also needed to remove sources of the minor Coulombic inefficiency that seems to be being "electrolyzed away" with increasing cycle number. Additives and other components will also be investigated to further improve the battery performance of this ternary electrolyte.

The instability typical of LiPF6-containing electrolytes at $\mathrm{T}>50^{\circ} \mathrm{C}$ is a matter of salt, not solvent, and studies with other anions such as BF3CF3- and their PF6- mixtures in purified solvents are desirable.

Following the demonstrations of Amine and co-authors,[2] it is certain that the fire hazard with lithium-ion batteries can be reduced (though not eliminated) by the high sulfone content (decreased hydrocarbon content) of our cells whose electrochemistry now seems so promising. The DMC cosolvent will, unfortunately, continue to determine the flash point, as stressed by Eshetu et al.[23] In future work we hope to collaborate with laboratories specializing in safety testing to determine how serious a problem this is. Sulfone-based solvents were unfortunately not included in the detailed fire hazard study of Eshetu et al.

\section{Acknowledgements}


This work was supported by the Assistant Secretary for Energy Efficiency and Renewable Energy, Office of Vehicle Technologies of the U.S. Department of Energy under Contract No. DE-AC02-05CH11231, Subcontract No. 6920968 under the Batteries for Advanced Transportation Technologies (BATT) Program. We thank colleague and dielectric relaxation specialist, Ranko Richert, for his providing, by direct measurements, unambiguous values of the dielectric constants for the solvents used in this work.

\section{References}

[1] L.G. Xue, K. Ueno, S.Y. Lee, C.A. Angell, Journal of Power Sources, 262 (2014) 123128.

[2] A. Abouimrane, L. Belharouak, K. Amine, Electrochem. Commun., 11 (2009) 10731076 .

[3] J. Máca, J. Vondrák, M. Sedlař́ková, ECS Trans. , 48 (2014) 135-142.

[4] J. Kagimoto, H. Tokuda, K. Takeda, Y. Sakata, T. Kawai, M. Ue, in: The 52nd Battery Symposium in Japan, Tokyo, Japan (Oct. 17-20), 2011, pp. 11.

[5] K. Xu, C.A. Angell, Journal of the Electrochemical Society, 145 (1998) L70-L72.

[6] N. Shao, X.G. Sun, S. Dai, D.E. Jiang, Journal of Physical Chemistry B, 115 (2011) 12120-12125.

[7] L.-D. Xing, J. Vatamanu, O. Borodin, S.G. D., D. Bedrov, J. Phys. Chem. C, 116 (2012) 23871-23881: DOI: 23810.21021/jp3054179.

[8] Q.M. Zhong, A. Bonakdarpour, M.J. Zhang, Y. Gao, J.R. Dahn, Journal of the Electrochemical Society, 144 (1997) 205-213.

[9] K. Amine, H. Yasuda, M. Yamachi, Electrochemical and Solid State Letters, 3 (2000) 178-179. 
[10] K. Xu, Chemical Reviews, 114 (2014) 11503-11618.

[11] S.-Y. Lee, K. Ueno, C.A. Angell, J. Phys. Chem. C, 116 (2012) 23915-23920

[12] K. Xu, C.A. Angell, Journal of the Electrochemical Society, 149 (2002) A920-A926.

[13] W. Xu, A.J. Shusterman, M. Videa, V. Velikov, R. Marzke, C.A. Angell, Journal of the Electrochemical Society, 150 (2003) E74-E80.

[14] X.-G. Sun, C.A. Angell, Electrochem. Commun., 7 (2005) 261-264.

[15] W. *Xu, E.I. Cooper, C.A. Angell, J. Phys. Chem. B, 107 (2003) 6170-6178.

[16] M.S. Miran, H. Kinoshita, T. Yasuda, M.A.B. Susan, M. Watanabe, Phys. Chem. Chem. Phys., 14 (2012) 5178-5186.

[17] A. von Cresce, K. Xu, Journal of the Electrochemical Society, 158 (2011) A337-A342.

[18] S.R. Li, C.H. Chen, J.R. Dahn, Journal of the Electrochemical Society, 160 (2013) A2166-A2175.

[19] J. Demeaux, E. De Vito, D. Lemordant, M. Le Digabel, H. Galiano, M. CaillonCaravanier, B. Claude-Montigny, Physical Chemistry Chemical Physics, 15 (2013) 2090020910.

[20] S.Y. Li, W. Zhao, X.L. Cui, H.M. Zhang, X.X. Wang, W.X. Zhong, H.X. Feng, H.N. Liu, Electrochimica Acta, 129 (2014) 327-333.

[21] C.L. Campion, W.T. Li, B.L. Lucht, Journal of the Electrochemical Society, 152 (2005) A2327-A2334.

[22] C. Schreiner, S. Zugmann, R. Hartl, H.J. Gores, Journal of Chemical and Engineering Data, 55 (2010) 4372-4377.

[23] G.G. Eshetu, S. Grugeon, S. Laruelle, S. Boyanov, A. Lecocq, J.-P. Bertrand, G. Marlair, Physical Chemistry Chemical Physics, 15 (2013) 9145-9155. 
[24] V.S. Kolosnitsyn, L.V. Sheina, S.E. Mochalov, Physicochemical and Electrochemical Properties of Sulfolane Solutions of Lithium Salts, 44 (2008) 575-578. 


\section{Figure captions}

Figure 1. Schematic presentation of the design of sulfone-carbonate ternary electrolyte.

Figure 2. Conductivities of various solutions of sulfone-containing binary and ternary solutions, emphasizing those containing the second sulfone component of higher dielectric constant, DMS. The conductivity deficit vs all-carbonate electrolytes is significantly reduced and (see below) ionicity advantage is increased.

Figure 3. DSC thermogram for the reheating at $20 \mathrm{~K} \mathrm{~min}^{-1}$ of the electrolyte of composition given in the legend, showing low glass transition temperature $\left(-108^{\circ} \mathrm{C}\right)$ crystallization of the most rapidly nucleating crystal (identity unknown) at $-70^{\circ} \mathrm{C}$ and (equilibrium) liquidus temperature at $-15^{\circ} \mathrm{C}$. Crystallization during slow cooling $\left(1 \mathrm{~K} \mathrm{~min}^{-1}\right)$ thus cannot occur above $-15^{\circ} \mathrm{C}$ and (in small DSC sample pans) does not occur before $-31^{\circ} \mathrm{C}$.

Figure 4. Walden plot for assessing the ionicity of conducting solutions. Fully ionic solutions have conductivities that fall on the ideal line established from aqueous solution date (1M KCl solution). Data from Kolosnitsyn et al.[24] would suggest that $1 \mathrm{M} \mathrm{LiPF}_{6}$ in sulfolane solution, is almost $100 \%$ ionic, i.e. fully dissociated, but that the less viscous, more highly conducting, solutions obtained by addition of low molecular weight lower dielectric constant co-solvents, may have as many as $90 \%$ of their ions in association complexes (ion pairs or higher aggregates)

Figure 5. Cyclic voltammograms of $1 \mathrm{M}$ solutions of $\mathrm{LiPF}_{6}$ in different solvents for electrochemical stability characterization, indicating that (EMS85-DMS15)-DMC is more 
stable against oxidation than EMS-DMC. The anodic side is magnified and shown on the right.

Figure 6. (a) The typical charge/discharge behavior of LNMO electrode with $1 \mathrm{M} \mathrm{LiPF}_{6}$ in (EMS85-DMS15)-DMC, collected at $200^{\text {th }}$ cycle, $0.2 \mathrm{C}$ rate, showing two distinct discharge plateaus for $\mathrm{Ni}^{2+} / \mathrm{Ni}^{3+}$ and $\mathrm{Ni}^{3+} / \mathrm{Ni}^{4+}$, at about $4.6 \mathrm{~V}$ and $4.7 \mathrm{~V}$, respectively; (b) and (c) display the cycling performance with respect to capacity retention, and coulombic efficiency, respectively. The data of EMS-DMC are also included for comparison. (d) Cycling stability of two batteries with $1 \mathrm{M} \mathrm{LiPF}$ in (EMS85-DMS15)-DMC (1:1 by wt.) electrolyte. Battery 1 was from Figure 5b that continuously cycled 300 times; With Battery 2, cycling was arrested after 200 cycles, and then resumed after storage for 2 months.

Figure 7. (a) Illustration of the collapse of the discharge capacity retention of the LNMO half-cell of Figure $5 \mathrm{c}$ when tested at $55^{\circ} \mathrm{C}$. The collapse is due to $\mathrm{PF}_{6}^{-}$thermal instability is illustrated by the results in part b. (b) Discharge capacity results for Li/LMNO half cell using the electrolyte of part a except for replacement of $\mathrm{LiPF}_{6}$ by the more stable $\mathrm{LiBF}_{4}$. The cell was cycled 20 times at ambient before raising the temperature to $55^{\circ} \mathrm{C}$. It is seen that the increase of temperature had no effect on the capacity retention, although it did lower the coulomb efficiency. 


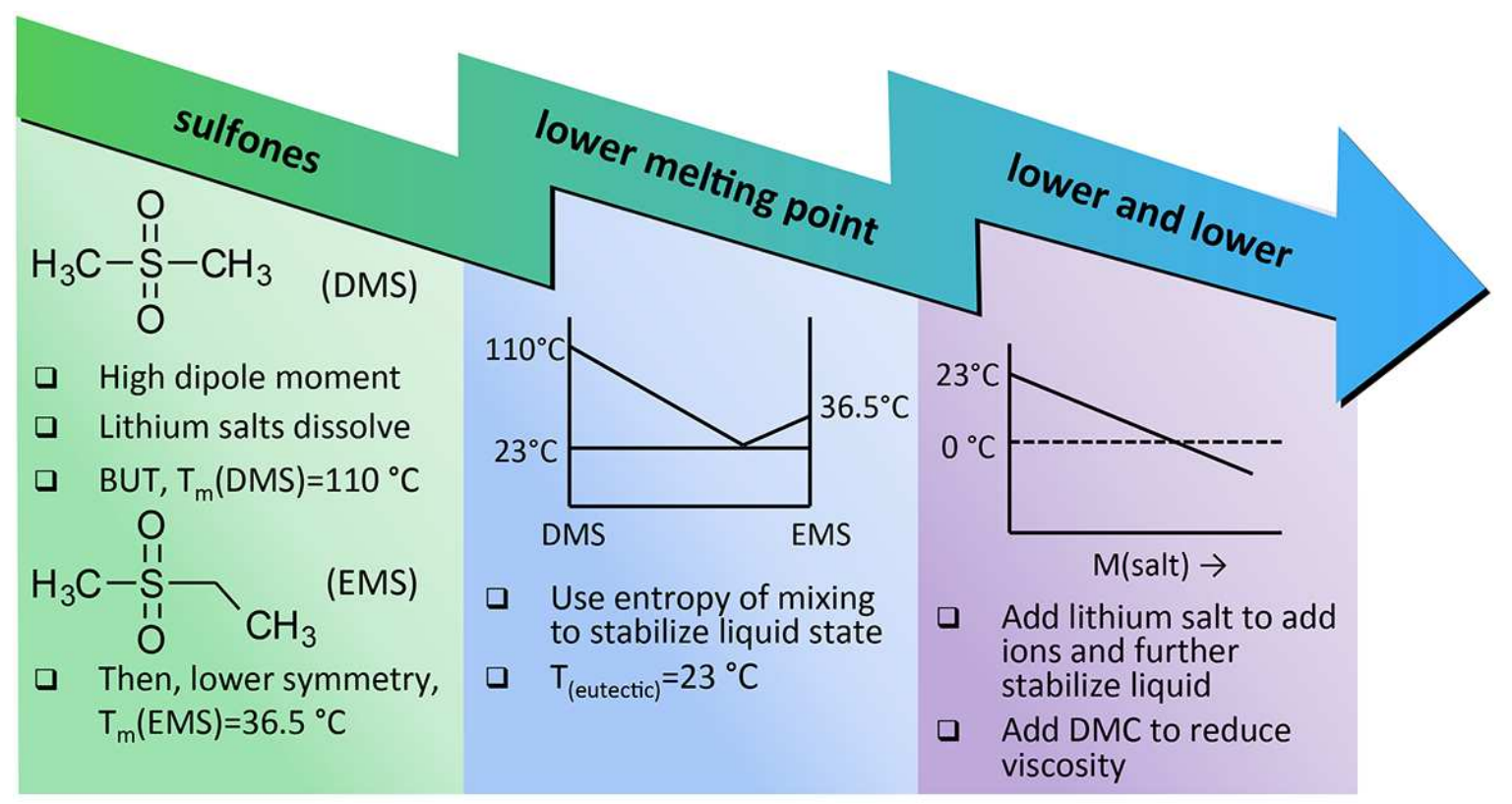

Figure 1. Schematic presentation of the design of sulfone-carbonate ternary electrolyte. 


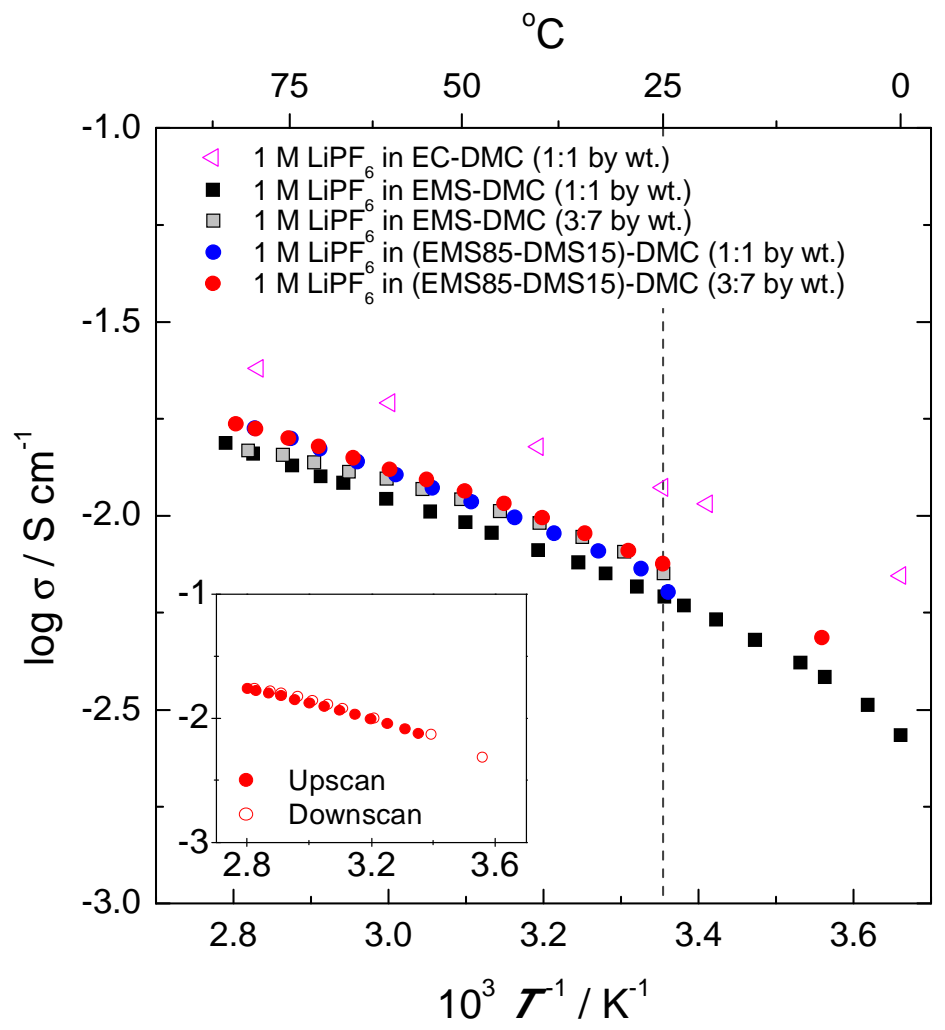

Figure 2. Conductivities of various solutions of sulfone-containing binary and ternary solutions, emphasizing those containing the second sulfone component of higher dielectric constant, DMS. The conductivity deficit vs all-carbonate electrolytes is significantly reduced and (see below) ionicity advantage is increased. 


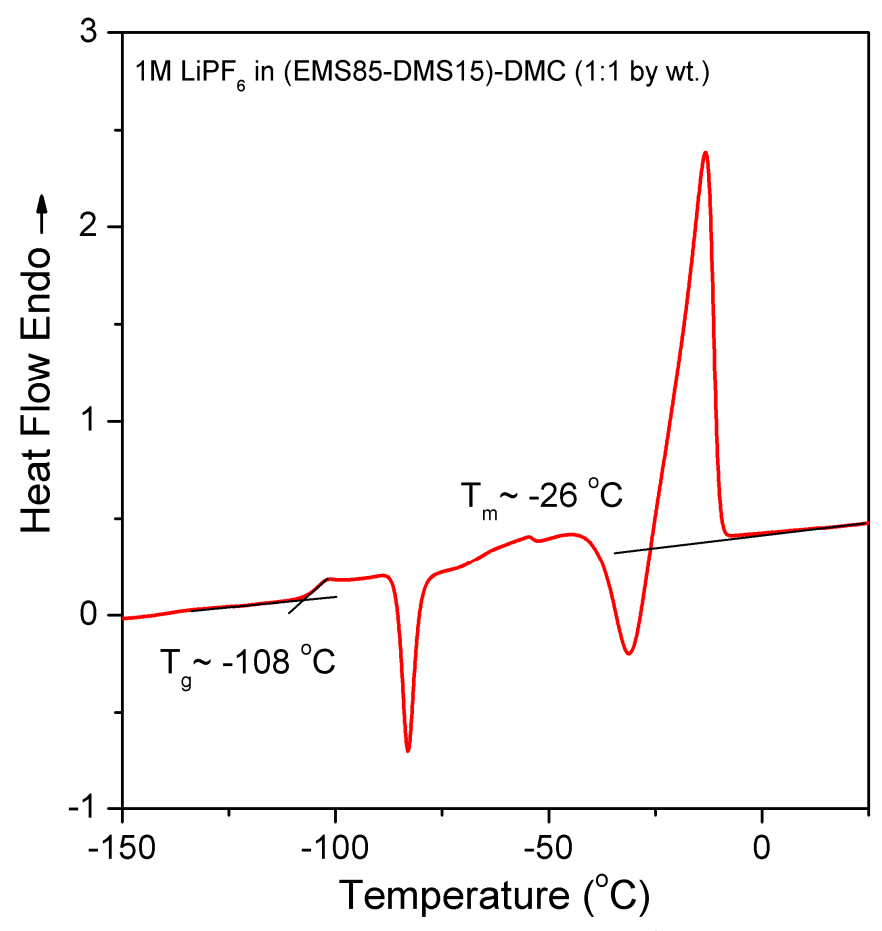

Figure 3. DSC thermogram for the reheating at $20 \mathrm{~K} \mathrm{~min}^{-1}$ of the electrolyte of composition given in the legend, showing low glass transition temperature $\left(-108^{\circ} \mathrm{C}\right)$ crystallization of the most rapidly nucleating crystal (identity unknown) at $-70^{\circ} \mathrm{C}$ and (equilibrium) liquidus temperature at $-15^{\circ} \mathrm{C}$. Crystallization during slow cooling $\left(1 \mathrm{~K} \mathrm{~min}^{-1}\right)$ thus cannot occur above $-15^{\circ} \mathrm{C}$ and (in small DSC sample pans) does not occur before $-31^{\circ} \mathrm{C}$. 


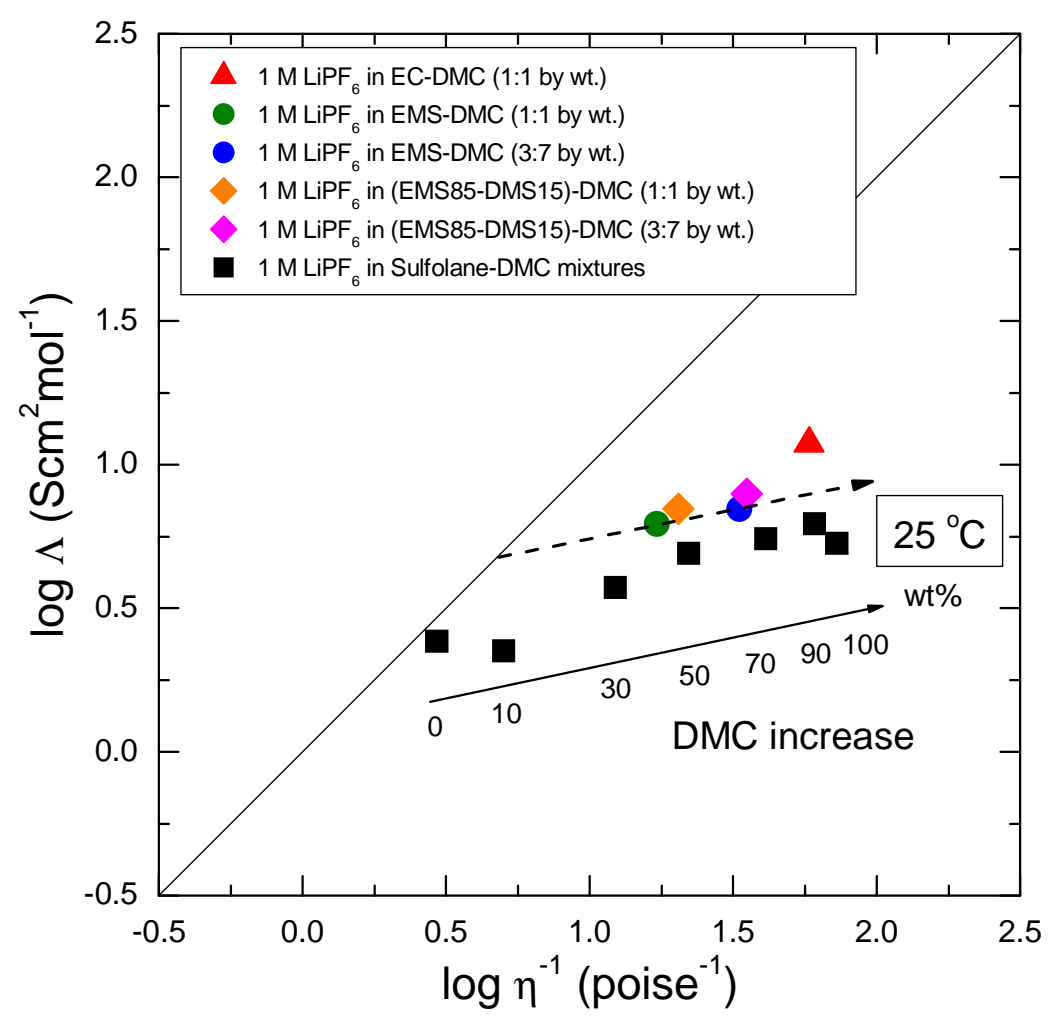

Figure 4. Walden plot for assessing the ionicity of conducting solutions. Fully ionic solutions have conductivities that fall on the ideal line established from aqueous solution date $\left(1 \mathrm{M} \mathrm{KCl}\right.$ solution). Data from Kolosnitsyn et al.[24] would suggest that $1 \mathrm{M} \mathrm{LiPF}_{6}$ in sulfolane solution, is almost $100 \%$ ionic, i.e. fully dissociated, but that the less viscous, more highly conducting, solutions obtained by addition of low molecular weight lower dielectric constant co-solvents, may have as many as $90 \%$ of their ions in association complexes (ion pairs or higher aggregates) 

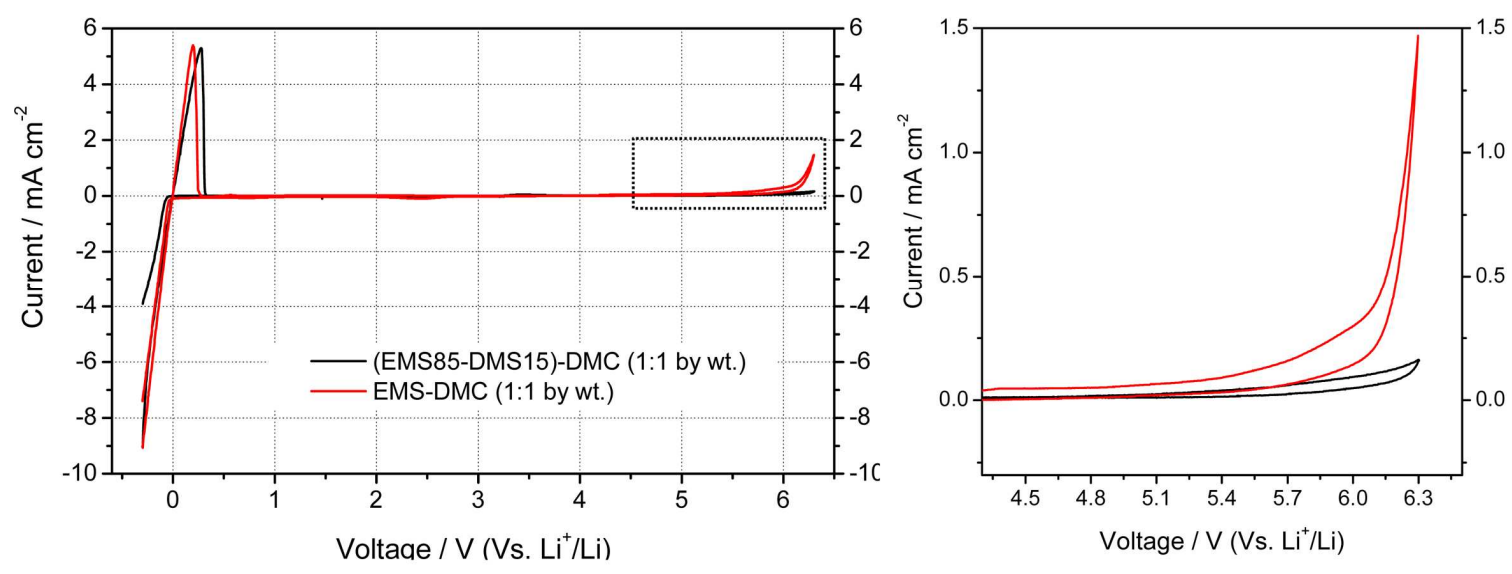

Figure 5. Cyclic voltammograms of $1 \mathrm{M}$ solutions of $\mathrm{LiPF}_{6}$ in different solvents for electrochemical stability characterization, indicating that (EMS85-DMS15)-DMC is more stable against oxidation than EMS-DMC. The high potential side is magnified and shown on the right. 

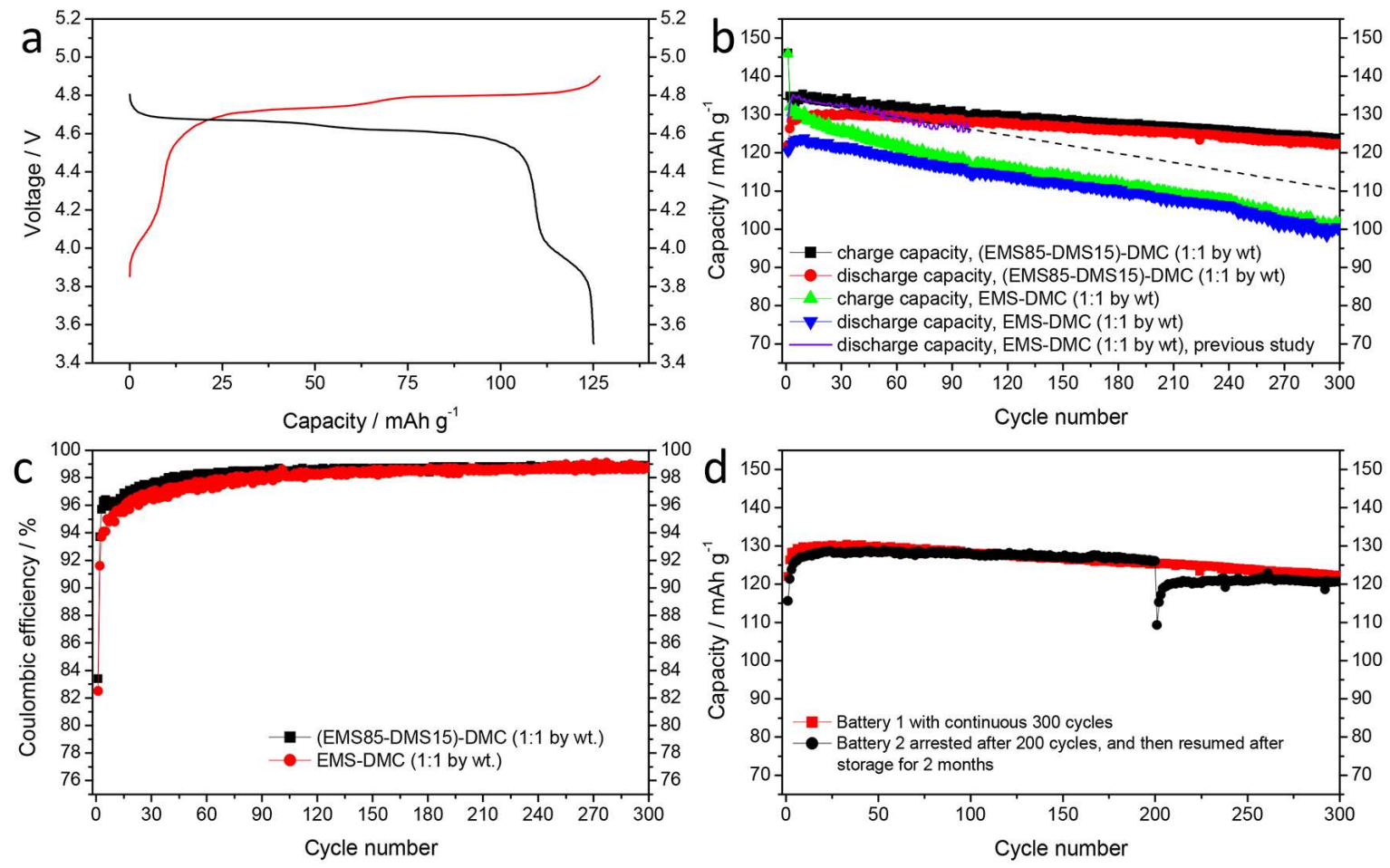

Figure 6. (a) The typical charge/discharge behavior of LNMO electrode with $1 \mathrm{M} \mathrm{LiPF}_{6}$ in (EMS85-DMS15)-DMC, collected at $200^{\text {th }}$ cycle, $0.2 \mathrm{C}$ rate, showing two distinct discharge plateaus for $\mathrm{Ni}^{2+} / \mathrm{Ni}^{3+}$ and $\mathrm{Ni}^{3+} / \mathrm{Ni}^{4+}$, at about $4.6 \mathrm{~V}$ and $4.7 \mathrm{~V}$, respectively; (b) and (c) display the cycling performance with respect to capacity retention, and coulombic efficiency, respectively. The data of EMS-DMC are also included for comparison. (d) Cycling stability of two batteries with $1 \mathrm{M} \mathrm{LiPF}_{6}$ in (EMS85-DMS15)-DMC (1:1 by wt.) electrolyte. Battery 1 was from Figure 5b that continuously cycled 300 times; With Battery 2, cycling was arrested after 200 cycles, and then resumed after storage for 2 months. 

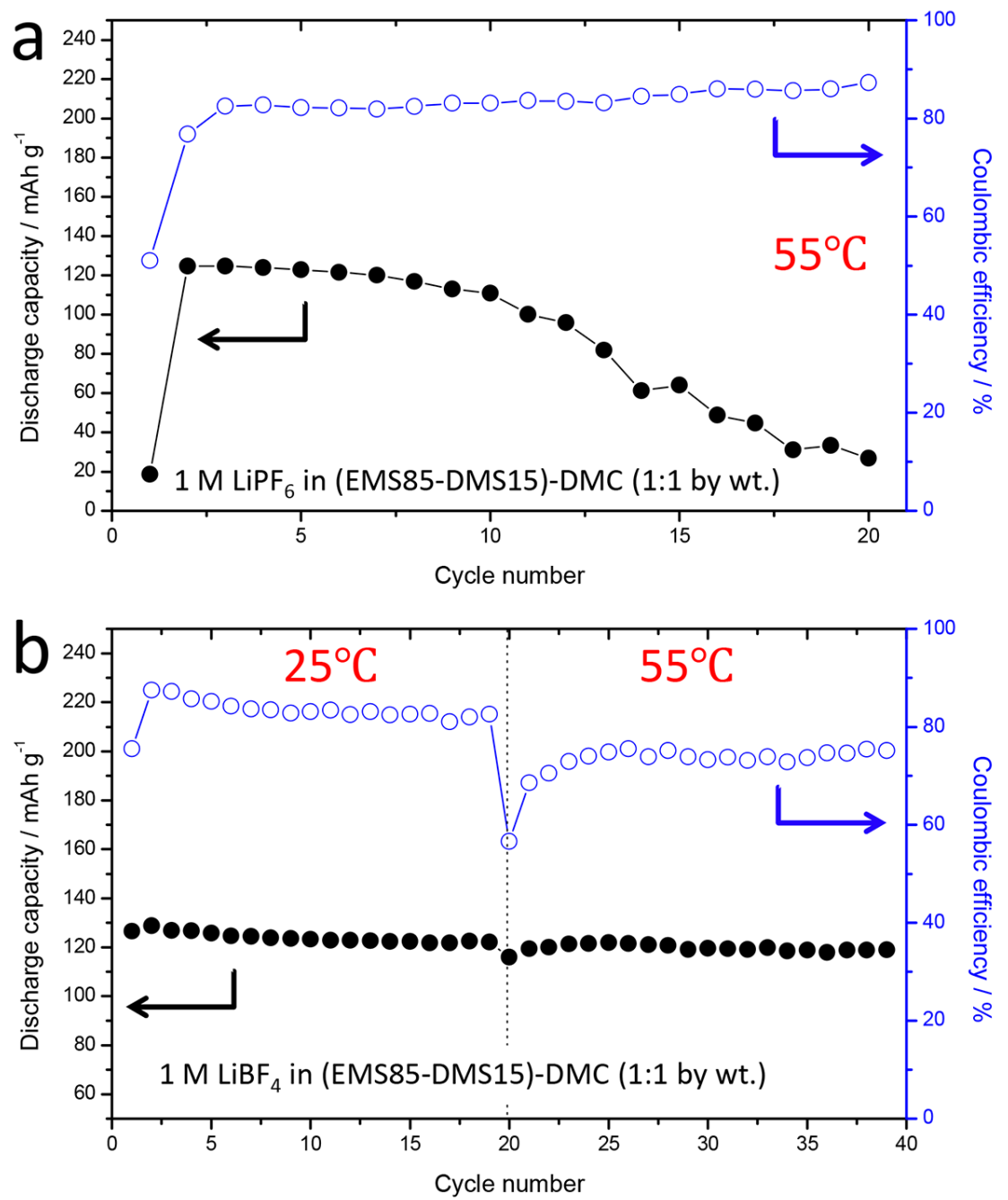

Figure 7. (a) Illustration of the collapse of the discharge capacity retention of the LNMO half-cell of Figure $5 \mathrm{c}$ when tested at $55^{\circ} \mathrm{C}$. The collapse is due to $\mathrm{PF}_{6}{ }^{-}$thermal instability is illustrated by the results in part b. (b) Discharge capacity results for Li/LMNO half cell using the electrolyte of part a except for replacement of $\mathrm{LiPF}_{6}$ by the more stable $\mathrm{LiBF}_{4}$. The cell was cycled 20 times at ambient before raising the temperature to $55^{\circ} \mathrm{C}$. It is seen that the increase of temperature had no effect on the capacity retention, although it did lower the coulomb efficiency. 